\title{
INESTABILIDAD TERRITORIAL Y CONFLICTOS EN LA NUEVA EUROPA. TAYIKISTÁN, ¿LA ÚLTIMA FRONTERA DE EUROPA?. CAUSAS Y POLÍTICAS DE GESTIÓN DEL CONFLICTO TAYIKO
}

\author{
Nora SAINZ GSELL \\ Universidad Autónoma de Barcelona
}

Hace más de una década, en noviembre de 1990 los Jefes de Estado y/o Gobierno de todos los estados europeos (a excepción de Albania y de Andorra) más Estados Unidos y Canadá firmaban la Carta de París para una Nueva Europa $(\mathrm{CP})$ en el marco de la Organización para la Seguridad y la Cooperación en Europa (OSCE) ${ }^{1}$. Este documento anunciaba el fin de la división europea actuando como un verdadero tratado de paz que ponía fin tanto a la Segunda Guerra Mundial como a la guerra fría. La CP explicitaba la aspiración a "recrear" el Viejo Continente, una Nueva Europa, como entidad política a partir de la democracia, la paz y la unidad. Sin embargo, la idea de esa Europa democrática (apertura a la democracia liberal), unida (desaparición de bloques) y pacífica (acuerdos militares alcanzados), pronto quedó profundamente afectada por una larga serie de tensiones y conflictos latentes y/o declarados que tuvieron en las guerras en la Antigua Yugoslavia o en las de Chechenia, ejemplos paradigmáticos.

En este marco se inscribe el presente trabajo, que persigue un doble objetivo: primero, presentar el mapa de la conflictividad en Europa; segundo, abordar uno de los conflictos, el de Tayikistán, y la gestión llevada a cabo por los actores internacionales para su resolución. Puede parecer paradójico que un trabajo que se centra en el marco de la Nueva Europa, analice un conflicto en una república centroasiática. Sin embargo, tal contradicción no existe, puesto que el conflicto tayiko representa uno de los modelos de confrontación presente en el espacio que, desde las relaciones internacionales y desde el ámbito de la seguri-

\footnotetext{
${ }^{1}$ Nombre que recibe a partir de enero de 1995 la Conferencia sobre la Seguridad y la Cooperación en Europa (CSCE). En este trabajo se utilizará la denominación OSCE, incluso cuando se haga referencia a la organización antes de la fecha indicada. Andorra y Albania se incorporarán $a$ posteriori a la OSCE, constituyendo una organización de cincuenta y cinco estados, incluídas todas las repúblicas que conformaban la Unión Soviética.
} 
dad, se denomina la Europa paneuropea, la Europa euroatlántica-asiática o la "Europa de Vancouver a Vladivostok".

La relevancia de este conflicto internacional radica en su complejidad "causal" (en su origen se encuentran cuestiones territoriales, culturales y de recursos) y en la participación de diversos actores internacionales para gestionarlo. La actuación de estados como la Federación Rusa, Estados Unidos, Irán, Turquía; y de organizaciones internacionales, Naciones Unidas, la OSCE, la Comunidad de Estados Independientes (CEI) o la propia Unión Europea (UE) dan indicios de la trascendencia que el conflicto posee. Amén de que se sitúa en una de las áreas o "complejo relacional geo-económico-estratégico de seguridad" más significativo del sistema internacional de post-guerra fría, el denominado Cáucaso-Mar Caspio-Asia Central (REITER, 2001). En ese contexto, Tayikistán aparece como la "frontera" oriental de Europa, el estado "tampón" frente al mundo islámico (ROY, 1998). El trabajo se ha divido en tres partes. La primera, se centra en identificar el mapa de la conflictividad existente en la Nueva Europa y la ubicación del caso tayiko. La segunda, analiza la situación del conflicto en la evolución del "orden" centroasiático, haciendo hincapie en los factores

\footnotetext{
${ }^{2}$ Es muy difícil definir Europa cuando se pretende analizar la seguridad en ella. Debido a la falta de límites geográficos convencionales o culturales (identidades europeas "puras") la respuesta sólo puede ser formulada desde el ámbito de lo que se ha denominado "imágenes o visiones", es decir a partir de la "reinterpretación" de la historia, de la cultura y de la geografía desde un marco de referentes políticos. Este marco político viene caracterizado por un importante proceso de "europeización" que ha distinguido las relaciones internacionales en Europa en los años setenta y, en particular, en los años ochenta. Este proceso, en especial de las relaciones de seguridad, que tuvo por objetivo reducir la importancia de lo militar en la seguridad y evitar las tendencias hacia la polarización; influyó de manera notable en el debate teórico sobre la "reinterpretación" de los elementos históricos, culturales y geográficos en la formulación de las distintas imágenes de Europa. En términos de seguridad, las "visiones" de Europa más importantes son: la Europa del Atlántico a los Urales; la Europa de Polonia a Portugal; la Europa occidental y la Europa de Vancouver a Vladivostok. Todas estas "Europas" son, de alguna manera, reales, cada una utiliza los elementos mencionado y que tienen diferentes implicaciones para la seguridad europea. La visión de "Europa de Vancouver a Vladivostok" es la "Europa de la OSCE" y es ante todo un concepto pragmático de Europa. No se basa exclusivamente en el nexo de valores históricos, culturales, religiosos, geográficos o políticos comunes entre cincuenta y cinco realidades (estados) diferentes, sino que parte de una configuración de Europa que ha sido construída políticamente (principios y valores comunes) y es producto del consenso de esas realidades diferentes. La Europa de Vancouver a Vladivostok incluye estados cuya no europeidad geográfica está fuera de toda duda (Estados Unidos y el Canadá) y otros que tienen una pertenencia geográfica europea y cultural discutidas (repúblicas asiáticas de la ex Unión Soviética). Pero estos estados, de una forma $u$ otra, tienen un papel real (y a veces determinante) que afecta las cuestiones europeas, de ahí la necesidad de su pertenencia a este espacio paneuropeo que es la OSCE. Esta visión es conocida, en términos de seguridad, como "área o región de seguridad europea".
} 
históricos, geoestratégicos y económicos que lo condicionan. La tercera estudia el proceso de gestión llevado a cabo.

\section{LA CONFLICTIVIDAD EN LA NUEVA EUROPA: UNA EUROPA FRACTURADA}

En el mapa europeo surgido en los años noventa, como consecuencia de los cambios producidos en el sistema internacional (unificación de Alemania, desintegración de la Unión Soviética, desmembración de la antigua Yugoslavia, división de Checoslovaquia), es posible identificar una serie de situaciones que pueden degenerar o lo han hecho en un conflicto ${ }^{3}$. Si se observa esas situaciones, es posible distinguir, claramente, dos grandes espacios de conflictos que abarcan lo que constituía la llamada Europa del Este. Por una parte, el que conformaba la ex Unión Soviética y, por otra, el que corresponde al resto de los estados de la Europa Central y Balcánica.

En el primer caso, el espacio ex soviético aparece como la zona generadora de más inestabilidad, de “inseguridad” en la Nueva Europa (CARRERE D'ENCAUSE, 1993). Dicho espacio, configurado en torno a un centro -Federación Rusa- y una periferia -resto de repúblicas que integraban la antigua Unión Soviéticapresenta distintos modelos de confrontación (YAKEMTCHOUK, 1993). En general, se pueden observar tres grandes tipos. Los conflictos y/o crisis que enfrentan a la periferia con el centro, ejemplos en este sentido, son el de los Estados Bálticos (Estonia, Letonia y Lituania) y sus disputas con la Federación por las minorías rusas y la presencia militar rusa en sus territorios, así como también el de Moldova, por esta última cuestión. Los conflictos que tienen lugar en repúblicas periféricas, la guerra civil en Tayikistán, o que enfrentan a repúblicas periféricas entre sí, no con el centro, como la disputa entre Armenia y Azerbaiyán por el territorio del Alto Karabaj; pero en los que la Federación Rusa ha desempeñado diferentes papeles (mediador, gestor, aliado, enemigo). Por último, las crisis que afectan al propio centro del espacio ex--soviético, siendo las guerras secesionistas en Chechenia la ilustración más relevante ${ }^{4}$.

\footnotetext{
${ }^{3}$ En 1992, en la mayoría de los documentos generados por las Organizaciones internacionales se cita como tensiones potenciales o reales las siguientes: el reintegro de los derechos de ciudadanía y de propiedad a los alemanes y a los húngaros expulsados de Checoslovaquia por los decrteos Benes en 1945-1946; por el mismo motivo a los italianos expulsados de Istria (actuales Eslovenia y Croacia) en 1945, los problemas fronterizos y de minorías entre Grecia y Albania, y los problemas greco-turcos en el Mar Egeo y la cuestión chipriota (RAMELOT Y REMACLE, 1995).

${ }^{4}$ Para algunos autores, los conflictos en el Cáucaso son esencialmente identitarios con una expresión étnica. La identidad es la conciencia de la existencia de una comunidad que posee simultáneamente los elementos constitutivos siguientes: una colectividad bajo un nombre propio; un mito o sujeto de descendencia común; una memoria histórica común; uno o varios elementos
} 
En el segundo caso, el de la Europa Central y Balcánica (después de las guerras yugoslavas), la cuestión más significativa de generar conflictividad ha sido la existencia de minorías nacionales en algunos de los estados (magiares en Eslovaquia y Rumanía, eslovacos en Hungría, turcos en Bulgaria, albaneses en la Antigua República Yugoslava de Macedonia, alemanes en la República Checa, etc.) que ha supuesto importante tensiones. Si bien, en el marco de la ex Unión Soviética, también el tema de las minorías, especialmente rusófonas, ha generado conflictos, el proceso de gestionarlos ha sido diferente. La presencia de la Federación Rusa, como actor significativo (hegemón) en la zona ha condicionado profundamente toda la política llevada a cabo para la solución de la cuestión. En guerra fría, el tema de las minorías y de sus conflictos permaneció en estado de latencia, totalmente controlado por los distintos aparatos estatales, producida la disolución del Bloque del Este, la cuestión se convirtió en un asunto de relieve en las relaciones intraeuropeas, cobrando especial connotación con motivo del inicio del proceso de ampliación de la UE en 1993. La existencia de minorías nacionales en el seno de algunos de los estados candidatos a la incorporación a la UE ha constituído un tema-problema sensible en la agenda negociadora comunitaria. La ampliación de la UE a ocho países del Este (Eslovaquia, Eslovenia, Estonia, Hungría, Letonia, Lituania, Polonia, República Checa) más Chipre $^{5}$ y Malta, implicará la incorporación de más de cien millones de personas, de los que, casi el diez por ciento, constituyen grupos étnicos minoritarios. En el caso de la Europa Central y Balcánica, respecto a minorías y de candidatos a la UE se puede hablar de conflictos cuya gestión está encaminada a una solución pacífica. En este sentido, hay que mencionar un hecho significativo de

\footnotetext{
culturales netamente distintivos; una asociación con una tierra natal; la existencia de un sentido de solidaridad entre sectores significativos de la población. Mozaffari establece una tipología de conflictos presentes en el Cáucaso: a. Conflictos étnicos irredentistas, generalmente entre dos estados independientes sobre una entidad territorial habitada por dos grupos étnicos diferentes pertenecientes respectivamente a los dos estados antagonistas, por ejemplo el del Alto Karabaj que enfrenta a Armenia y Azerbaiyán (fuera del Cáucaso, el conflicto chipriota entre Grecia y Turquía o el de Cachemira entre India y Pakistán). b. Conflictos secesionistas de carácter étnico, entre dos o más entidades étnicas las cuales están incorporadas en el seno de un mismo estado independiente, como los de Abjazia, de Osetia del Sur y en menor medida el de Adzharia en Georgia (el caso de Bangladesh en Pakistán). c. Conflictos étnicos anticoloniales, que a diferencia de los secesionistas, cuyo objetivo es la desintegración territorial del estado independiente, pero no colonial (Pakistán en el caso de la secesión de Bangladesh), el fin de los conflictos anticoloniales es el cese del hecho colonial. Los conflictos existentes en el Cáucaso Norte entre diversas entidades étnicas, chechenos, ingushes, daguestaníes, etc., y la Federación Rusa pueden ser clasificados como de conflictos coloniales, ya que las entidades mencionadas no aceptaron jamás la dominación rusa (MOZAFFARI, 1995, 208-216).

${ }^{5}$ La futura pertenencia de Chipre a la UE supone la incorporación al seno comunitario de un conflicto de guerra fría, que podría aparecer como un posible desestabilizador.
} 
valor político, el papel que el propio proceso de ampliación ha desempeñado ${ }^{6}$. Ha servido como un catalizador, un revulsivo para que los candidatos modificasen y "democratizacen" sus políticas respecto a los grupos minoritarios presentes en su territorio. La ampliación ha tenido valor per se.

Esta constatación de espacios de conflictividad y de medios pacíficos o violentos de resolución, lleva a hablar, si se considera la Europa Occidental, de una nueva "división" europea en post-guerra fría. La de una Europa fracturada en una "zona de paz" y en una "zona de confusión". La "zona de paz" en Europa coincidiría con la de un área en proceso de regionalización, en la que los estados que la conforman, democracias liberales con alto desarrollo económico, no recurren al uso de la fuerza para dirimir sus conflictos (SINGER Y WILDAVSKY, 1993) y que desde las relaciones internacionales se identifica con el modelo de seguridad llamado "comunidad de seguridad" (DEUTSCH, 1957; ADLER Y BARNETT, 1998). La UE aparece como el ejemplo próximo a este modelo en la Nueva Europa. Las "zonas de confusión” coinciden con los territorios de la actual CEI.

\footnotetext{
${ }^{6}$ La UE no disponía de instrumentos específicos para actuar en el ámbito preciso de las minorías, para ello debió recurrir a los de otros marcos de cooperación regional, OSCE, Consejo de Europa $(\mathrm{CdE})$, y a acuerdos fuera del ámbito comunitario. Para abordar la cuestión de las minorías en los países candidatos, se utilizó un marco diplomático-jurídico, de carácter multi y bilateral, estructurado en torno a cuatro grandes ámbitos. a) Un conjunto de documentos que actúan como contexto normativo. Los más destacados son: el Documento de la Reunión de Copenhague sobre la Dimensión Humana de la OSCE (1990); la Declaración de Naciones Unidas sobre los derechos de las personas pertenecientes a minorías nacionales, étnicas, lingüisticas y religiosas (1992); y el Convenio-Marco para la protección de minorías nacionales del Consejo de Europa (en vigor desde 1998). Existen también, como referentes el Pacto Internacional de Derechos Civiles y Políticos, Artículo 27; el Protocolo Adicional al Pacto, el Convenio sobre eliminación de todas las formas de discriminación racial, la Convención de derechos de los trabajadores migrantes, el Convenio Europeo de los Derechos Humanos; y la Carta Europea de lenguas regionales o minoritarias. Respecto a la ampliación, el instrumento que actúa como parámetro para el tema de las minorías en la UE son los criterios de Copenhague. La evolución del cumplimiento de dichos criterios aparece en los Informes periódicos que presenta la Comisión Europea; b)Una serie de mecanismos e instituciones creada en la post-guerra-fría en el ámbito de algunas organizaciones, como la OSCE y el CdE; c)Los tratados bilaterales firmados entre 1992-1996 por algunos países comunitarios y de la Europa Central y Oriental para la protección de las minorías. Esta política de tratados bilaterales fue especialmente intensa en los primeros años noventa, siendo Alemania y Francia los principales impulsores de esta práctica. d)Un espacio diplomático que recogerá los tratados bilaterales y una serie de acuerdos concluídos entre los países de la Europa del Este y los países comunitarios, el llamado Pacto de Estabilidad (PdE), de 1995. En este sentido interesa destacar la doble dinámica generada entre la ampliación (el proceso como incentivador), por una parte y los instrumentos externos a la UE utilizados, por otra.
} 


\section{CONTEXTO GENERAL DEL CONFLICTO: APROXIMACIÓN AL ASIA CENTRAL}

El conflicto tayiko se sitúa en Asia Central, una de las zonas de la antigua Unión Soviética, junto al Cáucaso, que más atención ha suscitado en el sistema internacional. Es, tanto en su calidad de "agujero negro" (vacio dejado por el fin del orden soviético), y de espacio de "Gran Juego", generador de políticas por parte de los actores internacionales, un área estratégica en las relaciones internacionales. Está formada por cinco repúblicas ex-soviéticas, Kazajstán, Kirguistán, Tayikistán, Turkmenistán y Uzbekistán ${ }^{8}$, que poseen una serie de peculiaridades que han determinado las relaciones en la región -orden centroasiático- y de la región con el exterior (DJALILI Y KELLNER, 2001). En este sentido hay que apuntar condicionamientos de tipo geo-histórico sociales así como de política interna (debilidad de los estados) que influyen de manera significativa en la formulación de sus políticas exteriores y que determinan la actuación de actores internacionales tanto regionales como mundiales.

\section{Las dimensiones del orden centroasiático}

\section{a) La dimensión geo-histórico política}

La geografía define al Asia Central como esa inmensa zona comprendida al este y al sur por las montañas de Tian Shan, de Pamir y del Elbrouz, al oeste por el Mar Caspio y al norte tiene la característica fundamental de no tener fronteras naturales. Ninguna barrera se interpone entre las estepas kazajas y las planicies rusas (lo que es significativo en términos geopolíticos ya que todos los movimientos de conquista vendrán desde el norte). La geografía de la zona reúne tres tipos de paisajes. El de las montañas habitadas por poblaciones seminómades al norte (los kirguizos) y por sedentarios al sur (tayikos). El de las

\footnotetext{
${ }^{7}$ El calificativo de "Gran Juego" fue utilizado por Kipling para denominar las políticas llevadas a cabo por las grandes potencias del siglo XIX, Rusia y Gran Bretaña, en su lucha por el control de Asia Central y luego del Cáucaso, es ampliamente usado por los analistas internacionales en la actualidad, al igual que el de "agujero negro", popularizado por BRZEZINSKI (1997). Después de los atentados del 11 de setiembre de 2001, las dos regiones se han revalorizado aún más estratégicamente, observándose, una vuelta a la Geopolítca clásica en relaciones internacionales.

${ }^{8}$ La expresión "Asia Central" es bastante imprecisa si se considera desde el punto de vista geográfico. Para algunos estudiosos, especialmente historiadores, la expresión se utiliza para referirise a la zona que comprende las repúblicas ex -soviéticas, así como la República Popular de Mongolia (Mongolia Exterior) y las tres dependencias de China, que se conocen con el nombre de Región Autónoma de Mongolia Interior, Región Autónoma de Sinkiang-Uighur y Región Autónoma del Tibet. En este trabajo, a todos, los efectos se va a considerar a "Asia Central" como el área compuesta por las repúblicas centroasiáticas ex -soviéticas, dado que en 1993 las cinco repúblicas declararon oficialmente ser reconocidas bajo el término de Asia Central.
} 
cuencas de dos grandes ríos, el Amu Daria (al sur) y el Syr Daria (al norte), llamada Transoxiana, en dónde floreció una rica civilización urbana, de origen persófono, en ciudades como Samarcanda y Bujara, el corazón histórico del Asia Central. El de las estepas (conocido como arco de las estepas), que se extiende de la frontera de Irán a Mongolia, y poblado por tribus antiguamente nómades, hoy sedentarizadas de turkmenos (al oeste) y de kazajos (al norte y al sur). El rasgo geográfico más sobresaliente es su completo aislamiento de la influencia oceánica que ha condicionado el territorio y su explotación.

Históricamente, Asia Central ha desempeñado dos funciones distintas y hasta cierto punto contradictorias (HAMBLY, 1985, 6). Por una parte, la aridez predominante y la falta de vías de comunicación, la han convertido en un elemento de separación entre las civilizaciones que se ubican en su periferia (iraní, china, china, india, rusa). Por otra, ha sido un nexo débil, pero nunca roto, a través del cual esas civilizaciones adquirieron conocimiento unas de otras y establecieron comunicaciones entre ellas. La zona ha sido lugar de paso en la antigua Ruta de la Seda y de encuentro de civilizaciones, el del mundo persa y el del turco de las estepas. A pesar, de haber estado en contacto con las regiones que la rodean, el hecho es que, Asia Central, ha sido una zona del mundo relativamente impenetrable a las presiones exteriores.

Políticamente, la dominación rusa de la región comenzó en el siglo XVIII y se realizó en dos tiempos y con modalidades diferentes (RoY, 2001, 19-21). Primero, hacia las estepas del actual Kazajstán, de forma lenta, progresiva y relativamente pacífica (1713-1899), mediante la firma de una serie de tratados con los clanes y hordas kazajas (se aseguró la defensa rusa frente a posibles invasiones desde Mongolia mediante una línea de fortificaciones), produciéndose una "rusificación" de la zona. Segundo, hacia el sur, hacia la Transaxonia, llamada en la época Turkestán. A diferencia del caso anterior, Rusia debió enfrentarse a los intereses de Gran Bretaña, presente en la India y "valedora" del mundo musulmán. El dominio ruso se consolidaría mediante la lucha y la anexión (Kokand, 1863; emirato de Bujara, 1865; Jiva 1873; etc.). En esta región la presencia rusa no modificaría las estructuras sociales tradicionales. En la época soviética, se puso en práctica una política que consistió en fraccionar el conjunto turco-musulmán en distintas unidades adminitrativas y no fue hasta 1936 que se estableció el mapa definitivo de la zona. Las decisiones de Moscú estuvieron encaminadas siempre a evitar cualquier proyecto unitario en el Asia Central (VVAA, 1999). Las repúblicas se diseñaron de forma artificial, y un mismo grupo étnico quedó fraccionado en las diferentes repúblicas (por ejemplo, para debilitar al Tayikistán, Samarcanda y Bujara con mayoría de población tayika, quedaron en territorio del Uzbekistán). La Perestroika no se vivió en Asia Central de la misma manera que en el resto del espacio soviético y los procesos de independencia en 
1991, no fueron iniciados por los dirigentes políticos locales, se produjeron por la propia desintegración de la Unión Soviética (no existieron grupo o formaciones nacionalistas que luchasen contra el "poder central" o "colonizador"). Las repúblicas centroasiáticas apoyaron el golpe de estado de agosto de 1991, que entre otros objetivos, pretendía evitar dicha desintegración (Taibo, 1999).

\section{b) La dimensión económico-estratégica}

La dimensión económico-estratégica de Asia Central está determinada por la existencia de importantes reservas de petróleo y de gas en el Mar Caspio (VIDAL-FOLCH, 1998). Por lo tanto, el control de las reservas, de la producción y de las rutas de salida de los recursos energéticos presentes, constituyen, hoy por hoy, la cuestión más importante de la región. De las antiguas repúblicas soviéticas vinculadas al Caspio, Azerbaiyán, Federación Rusa, Kazajstán y Turkmenistán, son las repúblicas kazaja y azerí las que disponen de mayores reservas potenciales de petróleo y la turkmena de gas. El gran tema respecto a los recursos es el de las vías de evacuación, es decir la construcción de oleoductos que permitan la salida y comercialización del petróleo. El tema constituye el núcleo duro de las relaciones, y de las rivalidades, entre las potencias regionales y mundiales (ROBERTS, 1996). Para los países productores, Kazajstan, Azerbaiyán, Turkmensitán, la evacuación del petróleo y del gas se convierte en una cuestión vital, ya que han diseñado una política económica basada en la explotación de su potencial energético. El transporte de cantidades importantes de crudo y la construcción de oleoductos y gasoductos constituyen elementos prioritarios en la agenda de negociaciones con sus vecinos, tanto para lograr estabilidad en las zonas en conflicto como para obtener el "permiso" de paso. Para los países por cuyos territorios (Georgia, Turquía, Federación Rusa, Irán, China) salen al mercado mundial el petróleo y el gas de la región, el derecho de "paso" sirve, a la vez, como baza negociadora y como elemento de presión frente a los productores $^{9}$ (FORSYTHE, 1996).

\footnotetext{
${ }^{9}$ En este "gran juego" de los hidrocarburos, la mención del entramado de las rutas y de los principales inversores, da una idea acabada de la complejidad de la cuestión. La primera de las rutas es la llamada vía rusa que ha ejercido un cuasi-monopilo para la salida del petróleo azerí, pero que ha sufrido directamente las consecuencias (sabotajes) de las guerras en Chechenia. Respecto a la salida del petróleo kazajo, la vía rusa de Tengiz-Novorossisk es el mayor proyecto en la zona (implica la participación de las más importantes empresas transnacionales, Chevron, Lukoil, Statoil, Delta, la Kazah State Oil, la Impex, la Japex y Mitsubishi Oil). La segunda es la via transcaspiana, que sortea el territorio ruso pasando por Georgia y Turquía. Es la vía privilegiada por los Estados Unidos y en la que empresas de esa nacionalidad (Amoco, Unocal, Exxon y Pensoil) controlan más del cincuenta por ciento de la extracción del petróleo azerí. La tercera es la vía iraní o vía sur. Es la más "racional" desde el punto de vista económico y la más corta ya que coloca el petróleo kazajo y al gas turkmeno directamente en el Golfo Pérsico, pero no cuenta con
} 
En la explotación de los recursos hay que sumar una controversia más entre los países ribereños, según se considere al Caspio como un lago (tesis que sostienen la Federación Rusa e Irán) y que implica una explotación concertada de recursos sin que ninguna de las partes tenga derecho de propiedad en exclusiva; o como un mar interior (Azerbaiyán, Kazajstán y en menor medida Turkmenistán) que supone la distribución de las aguas en diferentes categorías. La tesis "mar interior" es apoyada abiertamente por Estados Unidos, el primer inversor en la región. La polémica mar-lago complica aún más las relaciones en el área.

\section{Las repúblicas de Asia Central en post-guerra fría}

\section{a) Población y política}

Las repúblicas que constituyen Asia Central abarcan una superficie de casi cuatro millones de kilometros cuadrados (casi ocho veces la extensión de España). La cuantía de su superficie constrasta con la escasez de población y su distribución, apenas unos cincuenta millones de habitantes (diez menos que España), destacando la diferencia demográfica entre el estado más extenso y escasamente poblado (con una densidad de $6,2 \mathrm{hab} / \mathrm{km}^{2}$ ), Kazajstán, y el más pequeño en superficie Tayikistán, pero densamente poblado $\left(37,5 \mathrm{hab} / \mathrm{km}^{2}\right)$. El factor demográfico, como elemento de presión, desempeñará un papel significativo en las relaciones tayikas con sus vecinos. La existencia de centenares de nacionalidades (CARATINI, 1990), se refleja en la composición de la población, con presencia importante de minorías ${ }^{10}$, en algunos casos, de más o casi un tercio de la población del estado en que residen (rusos en Kazajstan y Kirguistán y rusos y uzbekos en Tayikistán).

La mayoría de los habitantes son de confesión islámica, musulmanes sunnitas, con presencia de minorías chiítas (ismaelitas). Después de acabada la guerra

el beneplácito de Washington. Se ha proyectado una variante de esta vía, por Afganistán (país fronterizo con Tayikistán), denominada vía paquistaní, que tras pasar por Pakistán llegaría a la India. La vía paquistaní, previo paso por Afganistán, contempla la posibilidad de construir un oleoducto y un gasoducto que sería ampliable hasta la India. Esta vía ha sido sopesada por la empresa estadounidense Unocal y los gobiernos de Japón, de la República de Corea y de Paquistán. La cuarta ruta es la china, oriental o Ruta de la Seda, cuyo objetivo es extraer el petróleo kazajo para colocarlo en los puertos de China y Japón del Pacífico (es el gran proyecto de la empresa china CNP).

${ }^{10}$ La composición de la población de las repúblicas, a 1989, da indicio de la diversidad: Kazajstán (kazajos 39,7\%, rusos 37,8\%, alemanes 5,8\%, ucranianos 5,4\%, tártaros $2 \%$, uzbekos $2 \%$ ); Kirguistán (kuirguizos 52,4\%, rusos 21,5\%, uzbekos 2,9\% , ucranianos 2,5\%); Tayikistán (tayikos $62,3 \%$, uzbekos $23,5 \%$, rusos 7,6\%, tártaros 1,4\%); Turkmenistán (turkmenos $72 \%$, rusos $9,5 \%$, uzbekos $9 \%$, kazajos $2,5 \%$ ); Uzbekistán (uzbekos $71,4 \%$, rusos $8,35 \%$, tayikos $4,7 \%$, kazajos $4,1 \%$, tárrtaros 2,4\%, karakalpakos 2,1\%). 
fría, la región ha sufrido un importante proceso de reislamización. A la existencia de un islam oficial, muy controlado por las autoridades, que existía durante la época soviética y que se mantiene en la actualidad, hay que sumar la presencia de un islam radical, que si bien es minoritario en el conjunto de las repúblicas, ha tenido una importante actividad y participación política. La presencia del islamismo radical es abiertamente manifiesta en Tayikistán, Uzbekistán y Kirguistán ${ }^{11}$.

De manera general, se puede afirmar que la transición política se desarrolló en la práctica como una tentativa de salida del modelo soviético (DJALILI, 2001). Los intentos de construcción de una soberanía e identidades nacionales se han hecho, progresivamente, contra el período soviético, sobre el reforzamiento del grupo étnico titular del nombre del país (con exclusión de las minorías) y el rechazo hacia la lengua del "colonizador" (políticas de des-rusificación) ${ }^{12}$. Sin embargo es difícil construirlas. Las repúblicas centroasiáticas a diferencia, por ejemplo, de las del Cáucaso, Georgia, Armenia, Azerbaiyán, no pueden referirse a su pasado pre-soviético, como entidades estatales ya que su organización se ha basado en kanatos y federaciones tribales, modelos lejanos al del estado moderno. Políticamente, hay continuidad, tanto en el modelo de administración estatal (se mantiene la centralización y las entidades autónomas son cada vez menos autónomas, se habla de "estados clónicos" de la Unión Soviética), como en las élites dirigentes, son las mismas del régimen soviético. La evolución de las repúblicas se ha decantado hacia regímenes autoritarios o semi autoritarios (Kirguistán) con el predominio de un partido único, y el papel preponderante del personalismo presidencial (culto a la personalidad, Islam Karimov en Uzbekis-

${ }^{11}$ Los principales movimientos radicales son el Partido del Renacimiento Islámico, legal en Tayikistán; el Movimiento Islámico de Uzbekistán (MIU), con clara implantación en el Valle de Fergana (fontera tayika-kirguiza-uzbeka) y con una importante política de oposición al gobierno de Karimov. El MIU está integrado por uzbekos, tayicos, chechenos, uigures y kirguizos; y el Partido de la Liberación Islámica, cuyo objetivo es la creación de un "califato para Asia Central.

${ }^{12}$ Se puede observar que la construcción de la identidad se realiza sobre la lengua de la etnia o minoría dominante con un claro rechazo a lo soviético-ruso, como por ejemplo, el cambio del alfabeto cirilico por el latino en Uzbekistán y Turkmenistán y el progresivo cambio al alfabeto arabo-persa en Kirguistán y Tayikistán. Existe la co-oficialidad de la lengua del país y el ruso, sin embargo, la obligación de conocer la lengua del país (hablada y escrita) para ocupar políticos y administrativos, deja fuera de la administración a la población de origen ruso. Esta es una de las causas, entre otras, de la emigración rusa de la región (en Turkmensitán hay un siete por ciento menos de población rusa en el 2000, respecto a la de 1990; y en Kirguistán de los novecientos mil rusos que había en 1991, quedan en la actualidad seiscientos setenta mil). También en la construcción de la identidad ha desempeñado un papel significativo la recuperación de tradiciones y fiestas de origen persa y de personajes históricos, Tamerlán, Ulug Bek (Uzbekistán). 
tán y Nursultán Nazarbaev en Kazajstán; presidentes cuasi vitalicios como Saparmurad Niazov en Turkmenistán).

Las características apuntadas, presencia del islamismo radical, existencia de minorías que reivindican representación gubernamental, regímenes autoritarios, junto al deterioro creciente de las condiciones económicas y sociales (una economía basada históricamente en el monocultivo y la sobre-explotación de la tierra, degradación medioambiental, desarrollo limitado por la "criminalización"mafias, tráfico de drogas y armas- de la economía, paro crónico, etc.) contribuyen a la debilidad de la legitimidad del estado en Asia Central.

\section{b) La inserción internacional}

Respecto a la inserción internacional, existe una estrecha vinculación entre la situación interna de las repúblicas centroasiáticas y la formulación de sus políticas exteriores. Estas entidades han estructurado sus relaciones internacionales, en el ámbito de la economía, de la política y sobre todo de la seguridad, en función de las debilidades y carencias que poseen (falta de recursos para la explotación de materias primas, insuficiencia de capacidad militar para la defensa del estado, inexistencia de medios y preparación ante graves situaciones medioambientales -contaminación, desertización-, escasez de experiencia y de burocracia diplomática, etc.); así como en la percepción de las "amenazas" (islamismo radical, terrorismo, desestabilización). Sin embargo, frente a problemas comunes no han puesto en práctica gestiones comunes, ha habido una resistencia a la gestión multilateral. En política exterior, las repúblicas, por separado, han orientado y buscado la cooperación con potencias regionales y mundiales; y con organizaciones internacionales que supliesen los "déficits de seguridad" apuntados. Así por ejemplo, las cinco forman parte de la CEI y en materia de seguridad militar, todas, a excepción de Turkmenistán (que ha proclamado su neutralidad en política internacional) firmaron el Tratado de Seguridad Colectiva (Tashkent) en 1992. Dicho Tratado, ha permitido la presencia militar de la Federación Rusa, de forma permanente en Tayikistán, asegurando el control y la defensa de la frontera más incierta de la CEI, la que tiene con Afganistán y la estabilidad del estado tayiko. No obstante, en los últimos años, Kazajstán, Uzbekistán y Kirguistán han reorientado sus alianzas militares hacia otros actores que también aparecen como "garantes" frente a las amenazas, Estados Unidos (con su política de instalación de bases militares) y la Alianza Atlántica, a través de la participación en la Asociación para la Paz. Las políticas de cooperación, constituyen, a su vez, la ocasión para la intervención y la formulación de políticas de potencias como Rusia, Turquía, Irán (PARENTEAU, 1995) y Estados Unidos (EBEL, 2001). Intervenciones que pueden ser leídas, a su vez, como manifestaciones de una lógica neo-imperialista, en el caso ruso; de una estrategia panturquista, en el turco; de un movimiento pan-islamista, en el iraní; o de una volun- 
tad hegemónica mundial, en el estadounidense, siendo Asia Central el espacio de confrotación de esas políticas (HALLIDAY, 1995).

\section{c) La presencia de actores internacionales}

Como se ha mencionado, Asia Central, en su calidad de zona de "Gran Juego" es una zona generadora de políticas por parte de los actores internacionales en la Nueva Europa, situación que se profundiza a partir del 11 de setiembre de 2001. Las potencias constituyen el primer grupo de actores presentes en la región, es decir actores para los que la cuenca del Mar Caspio y Asia Central constituyen su "zona natural de influencia", Federación Rusa, Irán y Turquía. Para los rusos, la región se inserta en el diseño de la política exterior rusa de lo que se conoce como el ámbito del "extranjero cercano" o zona de vital influencia (GRATCHEV, 1996). Los objetivos que la Federación persigue en este ámbito, son la preservación de una situación de dominación económica (control de recursos, por ejemplo), el afianzamiento de una zona de influencia que ponga freno a la expansión de otras potencias regionales (Irán y Turquía), hacer frente a eventuales amenazas exteriores (fundamentalismo islámico) y proteger los derechos de los rusos residentes en los países que conforman el área del extranjero cercano, la actual CEI (espacio que integra a doce de las exrepúblicas soviéticas). Los instrumentos de la política rusa en la zona han sido a) la creación de un sistema de solidaridad militar (Tratado de Tashkent) que no ha dado los resultados deseados; b) la percepción común de las "amenazas" a la seguridad y a la estabilidad de la zona, esencialmente el fundamentalismo islámico, la idea de Moscú es que Asia Central se convierta en una zona tampón del mundo islámico; c) una política económica activa con las repúblicas (TINGUY, 2001), especialmente desde la llegada de Putin al poder (establecimiento de la Comunidad Económica Euroasiática, 2001). En sus relaciones con las distintas repúblicas se puede destacar una estrecha vinculación con Tayikistán, la presencia militar de rusa, lleva a hablar de un "protectorado", con Kazajstán (comparte frontera) y Kirguistán hay unas relaciones "privilegiadas", por la presencia de minorías rusas; por último con Uzbekistán y Turkmenistán las relaciones han sido cada vez más distantes.

Para iraníes y turcos, la desaparición de la URSS dejó "las puertas abiertas" a posibles acciones en la zona. El objetivo de Irán, que mantiene relaciones satisfactorias con Rusia y Turkmenistán, es contrarrestar la política de aislamiento al que lo tiene sometido Estados Unidos. La influencia política iraní en la zona es relativamente limitada, a excepción de los tayikos, la mayoría de etnias son turcófonas y los únicos chiítas de Asia Central son los pamires de Tayikistán, que son ismaelitas. Más que una política ideológica, Teherán ha favorecido el desarrollo de lazos económicos con sus vecinos de Asia Central (construcción de un gasoducto entre Turkmenistán y el norte de Irán, inversiones en vías férreas 
turkmeno-iraníes en 1996; acuerdos con Kazakstán para la comercialización de su petróleo). Turquía se ha decantado por una actitud prudente y equilibrada hacia las repúblicas centrasiáticas frente a la presencia rusa. Su primigenia política de "Gran Hermano Turco" que había generado importantes roces con Moscú ha sido atemperada. Ankara ha establecido vínculos tanto en el ámbito del comercio y de la energía, la gran apuesta turca (con la ayuda estadounidense) ha sido que la salida de los hidrocaurburos del Caspio pasase por su territorio; como en el lingüístico y cultural (enseñanza del turco, becas, bolsas de estudios para alumnos, principalmente de universidades uzbekas, etc.).

China ha tenido un papel discreto pero continuado en la región después de la desintegración e la Unión Soviética. Sus objetivos inmediatos hacia la zona son limitar la actividad de los separatistas uigures (poblaciones turcófonas de Sinkiang) que habitan en Kirguistán (cuarenta mil) y Kazakstán (doscientos mil); solucionar de manera pacífica los diferendos fronterizos que tiene con los mencionados estados; y establecer relaciones económicas con una región rica en hidrocarburos (desde 1997 existen acuerdos con el gobierno kazajo para la explotación de yacimientos petrolíferos y la construcción de un oleoducto).

El segundo grupo, está formado por estados lejanos geográficamente a Asia Central pero que tienen significativos intereses políticos y económicos en la región, como es el caso de Estados Unidos. Este país ha definido la zona en términos de interés estratégico vital ${ }^{13} \mathrm{y}$ en consecuencia ha formulado sus objetivos. Estratégicamente, su política pasa por romper el dominio ruso, limitar la presencia iraní y favorecer y promover el papel turco. Políticamente, persigue favorecer la estabilidad en la región y desarrollar "solidaridades" en la lucha contra el tráfico de drogas y el terrorismo. Económicamente, su gran objetivo pasa por controlar y usufructurar las vías de salida de los recursos presentes; es el primer inversor en la región. Junto a Estados Unidos, también hay que señalar la presencia de Reino Unido, Francia, Alemania, Noruega, Corea del Sur, Israel y Japón, estados para los que Asia Central ocupa cada vez más un lugar significativo en sus políticas comerciales.

Un tercer grupo de actores es el de las organizaciones internacionales, presentes ya sea para gestionar los conflictos centroasiáticos -Naciones Unidas y la OSCE-, apoyar su gestión-UE- o por intereses económico-políticos $\mathrm{UE}^{14}$, Or-

${ }^{13}$ Después de los atentados del 11 de setiembre de 2001, el Cáucaso y Asia Central se han revalorizado estratégicamente. Pruebas de ello son: la existencia de asesores militares estadounidenses en Georgia para la lucha contra el terrorismo internacional y la instalación de bases militares en Kirguistán, Uzbekistán y Tayikistán.

${ }^{14}$ La UE, en tanto que "actor colectivo", ha tenido un papel marginal respecto del resto de actores. Los estados comunitarios han privilegiado y ejercido políticas hacia el área fuera del marco 
ganización de Cooperación de Shangai ${ }^{15}$, Alianza Atlántica. Un cuarto, y último grupo relevante de actores, está compuesto por las empresas transnacionales que se disputan la extracción y comercialización de las riquezas de la región, algunas ya mencionadas.

\section{TAYIKISTÁN: EL CONFLICTO Y SU GESTIÓN}

\section{Condicionamientos, actores y evolución del conflicto}

\section{a) Condicionamientos del conflicto}

Tayikistán fue producto de la puesta en práctica de las políticas de las nacionalidades llevada a cabo por la ex Unión Soviética. La denominación "tayiko" fue la denominación dada en 1924 por el régimen soviético a los persáfonos sunitas del Asia Central turcófona (GHEBALI, 1996, 301-310), estableciéndose la Región Autónoma de Tayikistán en el seno de Uzbekistán. En 1929, se transforma en una República de la Unión Soviética, pasando los territorios históricos de Samarcanda y Bujara (con casi un millón de personas de origen tayiko) a Uzbekistan. La república tayika fue el resultado de la conjunción de tres regiones muy diferentes, la de Leninabad (denominada después de 1991, Joyand), industrial, muy vinculada al Uzbekistán; la de Gharm, agrícola, con una economía basada exclusivamente en la explotación intensiva del algodón; y la región montañosa de Gorno-Badakhstan, de acceso difícil por sus peculiaridades geográficas. Tayikistán, con el noventa por ciento de su superficie ocupada por montañas, lo que condiciona su desarrollo, ha sido el país más pobre y menos industrializado de la Unión Soviética, dependiendo de la ayuda económica de Moscú.

La composición de su población es compleja, más del cuarenta por ciento lo forman minorías étnicas (uzbekos, rusos, tártaros, ucranianos), destacándose algunas regiones por la importante presencia uzbeka de origen turcófono (más del treinta por ciento) en Joyand, Gisar y Qurgan Teppa. La sociedad tayika ha es-

de la UE, siendo Gran Bretaaña, Francia y Alemania, los ejemplos destacados. No obstante, la UE, deficitaria en materia energética, ha establecido un programa de asistencia técnica y financiera, denominado TRACECA (Corredor Trasnporte Europa-Cáucaso, Asia) en el ámbito del programa TACIS (asistencia técnica de la UE a los nuevos estados independientes de la CEI y Mongolia). También existe el programa INOGATE para la evacuación de hidrocarburos. Los objetivos de estos programas son la promoción y el desarrollo de corredores de transporte del petróleo y el gas.

${ }^{15}$ La Organización de Cooperación de Shangai agrupa, desde 1996, a la Federación Rusa y a China con las repúblicas centroasiáticas, a excepción de Turkmenistán. El objetivo de la cooperación es abordar cuestiones y litigios fronterizos (chino-kazajo y chino-kirguizo), y temas como terrorismo, separatismo y tráfico de drogas. 
tado estructurada en torno a cuatro clanes que han desempeñado un papel relevante en la vida política del país. El de los joyandi al norte, en Leninabad; el de los kulyabi, al sur, en la frontera con Afganistán, los de Gharm, gharmis al sudeste y los pamires de la región Autónoma de Gorno-Badakhstan (con políticas secesionistas), al este. Durante la época soviética, el poder lo detentó el clan de los joyandi, con la participación más tarde, del de los kulyabi (los dos clanes conformaban el sesenta por cienta de la población de la república) con la consecuente, marginalización de los gharmis y los pamires. La Perestroika no fue bien recibida por la elite dirigente, una de las más conservadoras en el régimen soviético y la independencia fue acogida con resignación.

\section{b) El conflicto, los actores y su evolución}

Tayikistán proclamó su independecia en setiembre de 1991, subrogando el poder, la vieja nomenkaltura soviética, circunstancia que generaría la inmediata reacción de los sectores de población que habían sufrido una clara política de discriminación (gharmis y pamires). La oposición, anticomunista, nacionalista y proislámica, se constituyó en torno a distintas agrupaciones con diferentes objetivos políticos: el Movimiento Nacionalista del Renacimiento (Rastakhiz) que persigue una vuelta a las fuentes de la cultura tayika (persáfona); el Partido Democrático, cuyo fin es la des-sovietización política del país; el Partido del Renacimiento Islámico (en un principio no ligado a posturas fundamentalistas), que preconiza una vuelta a los valores islámicos y el grupo Lali-Badakhstan, que reclaman una mayor autonomía para el Gorno-Badakhstan.

De setiembre de 1991 a mayo de 1992, la confrontación entre las distintas fuerzas se desarrolló en la esfera política. Ante la presión de la oposición, el gobierno se vio obligado a convocar elecciones presidenciales, que ganaría el sector "oficialista", con Rahman Nabiev a la cabeza (un joyandi). La victoria, no reconocida por los perdedores, generó importantes manifestaciones y movilizaciones contra el gobierno elegido. A partir de este momento, se inició una dinámica que degeneraría, más tarde, en una confrontación abierta, una guerra civil, que ocasionaría, más de cincuenta mil muertos y quinientos mil desplazados. De nada sirvió la formación de un gobierno de unidad nacional (mayo 1992) que fue rechazado por los clanes detentadores históricos del poder (joyandi y kulyabi), colocando a uno de los suyos Imomali Rahmanov (kulyabi) en la jefatura del país. La violencia, generalizada en todo el Tayikistán, derivó en un conflicto abierto entre diferentes grupos clánicos, joyandis y kulyabis frente a gharmis y pamires, que sólo cesaría, merced a la intervención de la Federación Rusa (diciembre 1992). La asistencia militar directa de Moscú y, luego, por medio de la CEI, decantó la contienda a favor de joyandis y kulyabis. Sin embargo, la derrota de la oposición no puso fin al conflicto, al contrario, éste adoptó una nueva dimensión, "internacionalizándose". Se convirtió en una con- 
frontación con participación de actores no implicados directamente, pero con importantes intereses en la zona. Así es posible identificar, la intervención de Afganistán (gobierno talibán), la frontera más permeable de la CEI, con una importante presencia de tayikos en su población (tres a cuatro millones de personas) que acogió a parte de los vencidos; y, más discretamente, a Pakistán. Estados que se convertirían en centros dónde se armará la resistencia, pequeños grupos armados que realizarían constantes incursiones en territorio tayiko. También hay que mencionar a Irán, que apoyará a la Oposición Unificada de Tayistán (UTO), en menor medida, Turquía preocupada por la situación de las minorías turcófonas en la zona y Estados Unidos, Gran Bretaña y Francia que ven en la guerra una amenaza a la estabilidad en la zona. En cuanto a las organizaciones internacionales, la presencia de la CEI (apoyada por los cuatro vecinos de Tayikistán desde setiembre de 1993) se verá complementada por la actividad de Naciones Unidas y la OSCE, que intentarán poner en marcha negociaciones que encaminen el conflicto hacia una solución pacífica.

En paralelo a este proceso de internacionalización, el conflicto continuaría. En Dushambé, el clan joyandi es marginado del poder, y el gobierno tayiko promulga una Constitución (1994) a la medida de Rahmanov, que es elegido presidente en 1995. En 1996, la guerra se reactiva y la oposición, que había reemprendido progresivamente su actividad principalmente en el sur, llegaría a controlar casi un tercio del país. La intervención internacional de Naciones Unidas, la OSCE y la Federación Rusa, logra un alto el fuego. En 1997, por presión directa de Moscú, se alcanza un acuerdo, que permite el establecimiento de un gobierno de coalición, que descansa en un nacionalismo tayiko marcadamente anti-uzbeko y anti-talibán ${ }^{16}$. Las elecciones presidenciales de 1999 confirman el poder de Rahmanov y las parlamentarias de 2000 posibilitan una mínima representación de la oposición (partidos comunista e islamista). Los acontecimientos del 11 de setiembre de 2001 y la posterior guerra en Afganistán (contra los talibanes) han colocado en primera línea de interés regional a Tayikistán. Tanto Estados Unidos, Gran Bretaña y Francia tienen presencia activa (fuerzas militares, encargados de negocios, etc.) en territorio tayiko y han apoyado la firma de la ampliación del acuerdo de reconciliación nacional firmado en 1997 por el gobierno y la oposición (marzo 2002). En la actualidad, y de acuerdo a los compromisos alcanzados, se pueden observar algunos avances en materia de un desarme progresivo de las milicias y de cierta estabilidad que se observa en la economía. Aunque los grandes problemas del estado siguen es-

\footnotetext{
${ }^{16}$ La coalición con un setenta por ciento de los cargos de gobierno para los kuylabis, el resto para ghamirs y una mayor autonomía para los pamires, relega a los joyandis que buscan acercarse a Uzbekistán. El nacionalismo tayiko se fundamenta en torno a la lengua persa y la "nostalgia" por la pérdida de los territorios históricos de Bujara y Samarcanda.
} 
tando presentes: el desarrollo de una economía paralela basada en el tráfico de drogas y de armas; los derivados del regreso de los refugiados desde Afganistán y su integración; y el alto crecimiento demográfico que ha experimentado el país en estos últimos años (el mayor de la CEI).

\section{La gestión del conflicto}

La participación tardía de actores internacionales (otros estados y organizaciones internacionales) para mediar y/o gestionar el conflicto en Tayikistán se explica por distintas razones. El carácter de asunto interno (era un problema tayiko), la falta de experiencia y de instrumentos internacionales para hacer frente a los conflictos (los principios consensuados internacionalmente se dirigían a dirimir crisis de tipo interestatal y no intraestatal), y, el hecho de que Tayikistán, por razones estratégicas, económicas y de seguridad formaba parte de la zona vital de la Federación Rusa. De ahí, la dificultad de actuación. Sin embargo, una vez que el conflicto deviene en una guerra civil que afecta la estabilidad del resto de los vecinos (Uzbekistán, Kazajstán, Kirguistán, Turkmenistán, Afganistán, China), adquiere una nueva dimensión que posibilita la participación de otros actores, y en consecuencia, la internacionalización. En el caso tayiko, se pueden distinguir momentos en la evolución de la gestión del conflicto, cada uno con rasgos propios y distintos gestores actuando en paralelo: Naciones Unidas que prepara el terreno de las negociaciones; la OSCE, que se encargará de vigilar la puesta en práctica de lo negociado y formulará políticas de estructuración del estado; y la Federación Rusa que será el gran gestor permanente.

\section{a) Naciones Unidas y la Federación Rusa}

La responsabilidad de gestión del conflicto tayiko correspondió a Naciones Unidas y a la OSCE que se hicieron cargo por primera vez de una crisis que tenía lugar en el espacio exsoviético. Su actividad fue complementada con otros gestores oficiales, la CEI y "oficiosos", la Federación Rusa y en menor grado, Irán, Pakistán, Afganistán, Estados Unidos. En casi una década de gestión, el conflicto ha sido contenido, mediante compromisos renovados $(1997,2002)$, sin embargo su solución política definitiva no se ha alcanzado. En el caso tayiko, se pueden establecer etapas en su gestión, determinadas por el grado de "internacionalización" (incremento de actores) del conflicto. Se puede hablar de tres grandes períodos en la gestión. El primero, muy breve, es el que va desde el estallido de la guerra civil hasta la derrota de la oposición (mayo-diciembre 1992), con la Federación Rusa como único gestor, apoyando directamente a uno de los beligerantes. Sólo después de que Moscú controle la situación en Tayikistán, dejará paso a la entrada de las organizaciones internacionales. El segundo, 1993-1995, el más internacionalizado, el de las grandes rondas negociadoras, y en el que destaca la labor de Naciones Unidas en el ámbito del "estable- 
cimiento de la paz" (peace-making), y con una Misión de Observadores (MONUT), apoyada por la OSCE. Este es el período que, bajo el patrocinio de Naciones Unidas, tendrán lugar una serie de reuniones que convocan a una pléyade de actores (estados de la CEI, Rusia, Uzbekistán, Kazakstán y Kirguistán; estados fuera del marco CEI, Afganistán, Irán y Pakistán, Arabia Saudita y la OSCE como observadora). Producto de esas negociaciones fueron las reuniones de Moscú (abril 1993), en la que se fijaron los temas de la agenda (cuestiones políticas, humanitarias (desplazados) y constitucionales), la de Teherán (setiembre 1994) en el que se establecen las condiciones del alto el fuego; la de Islamabad (noviembre de 1994) y la de Almaty (junio 1995) en las que se profundizan las cuestiones relativas a la estructuración del estado tayiko. El tercero, a partir de 1995, es la puesta en práctica de lo acordado. Naciones Unidas "delega" en la OSCE y en la CEI la gestión del conflicto. Esta última había desplegado fuerzas colectivas de mantenimiento de la paz y colocado fuerzas (rusas) a lo largo de la frontera con Afganistán.

\section{b) La OSCE y la Federación Rusa}

El conflicto tayiko entra en la agenda de la OSCE (finales de 1993) durante la presidencia italiana de la organización, a propuesta de los países nórdicos, los estados comunitarios y esencialmente de Estados Unidos, para el que la guerra civil es una seria amenaza a la seguridad en la región euroasiática (denominación y noción utilizada constantemente por Washington desde el fin de la guerra fría). La OSCE es el foro idóneo para gestionar el conflicto dado su alcance paneuropeo (la "Europa de Vancouver a Vladivostock") y puesto que es la única que posee un entramado de diplomacia preventiva y de gestión de conflictos, consensuado por cincuenta y cinco estados ${ }^{17}$ en el marco de la Nueva Europa.

${ }^{17}$ Desde la Carta de París (1990), la OSCE ha desarrollado distintos instrumentos, es decir medios adecuados para evitar, gestionar y solucionar conflictos de modo pacífico, en función del estadio en el que se encuentre una situación-problema dentro de su área de cobertura. Dichos instrumentos se aplican en el ámbito de: la alerta temprana de las situaciones que puedan degenerar en crisis, la prevención de conflictos y la gestión de crisis. Así como instrumentos de alerta temprana se encuentran las consultas políticas periódicas llevadas a cabo en el seno de las estructuras (Consejo Ministerial (CM), Consejo Superior (CS), Reuniones de Revisión (RR), etc.) y de las instituciones de la Organización (por ejemplo, el Secretario General, la Oficina de las Instituciones Democráticas y de los Derechos Humanos (OIDDH) y el Alto Comisionado sobre las Minorías Nacionales (ACMN)). En el campo de prevención y de gestión de conflictos se cuenta con los mecanismos OSCE en el ámbito de la seguridad (arreglo pacífico de controversias Mecanismo de La Valetta-, situaciones de emergencia -Mecanismo de Berlín-, actividades militares no usuales -Mecanismo de Viena-) y de la dimensión humana (mecanismo de Moscú), así como también los grupos de gestión ad hoc y las misiones de relatores y de encuesta y de larga duración. 
La actuación de la OSCE en Tayikistán, por medio de una Misión (establecida en 1994), estará profundamente marcada por la evolución del conflicto, se podría hablar de un antes y un después, respecto del acuerdo de 1997. Desde un principio las tareas de la OSCE se encaminaron a apoyar y facilitar las negociaciones patrocinadas por Naciones Unidas y a partir de 1995 a facilitar el cumplimiento de los compromisos negociado (tareas de mantenimiento y de consolidación de la paz, peace-keeping y peace-building). En este sentido, su acción se dirigió especialmente a la creación y establecimiento de instituciones democráticas, comenzado por la elaboración de un proyecto de un proyecto de constitución; y a la atención de la situación de los refugiados (posibilitando su inserción en la sociedad tayika). Sin embargo, la labor de la OSCE se vio profundamente afectada por la escasa colaboración de las autoridades gubernamentales tayikas, los dirigentes se mostraron poco favorables a una democratización del estado que pudiese afectar el monopolio del poder. Asimismo el recrudecimiento de la guerra civil en 1996 y la negativa de Dushambé de mejorar las condiciones de la dimensión humana dentro del país (refugiados, prisioneros de guerra, situación de grupos minoritarios, etc), entorpecieron la gestión de la organización. Fue a partir de la firma del Acuerdo de Reconciliación Nacional (MosCÚ, 1997) cuando la OSCE recuperó su actividad. Ahora bien, con una estrategia, si se quiere, diferente a la llevada con anterioridad, ya que las cuestiones tayikas, pasaron a formar parte de una política global de la organización hacia Asia Central (GHEBALI, 2001). La Misión de la OSCE en Tayikistán fue suplantada por la labor de un Centro de carácter permanente en el país (se abren centros en las otras cuatro repúblicas) que colabora en la gestión del conflicto desde una óptica múltiple (aborda derechos humanos, instituciones democráticas, desplazados, cuestiones medioambientales, drogas, etc.). Es indudable, que tanto la gestión de Naciones Unidas como de la OSCE no hubiese sido posible sin la participación del gran "facilitador" de políticas en la zona, Rusia.

\section{BALANCE DE UNA GESTIÓN: ¿TAYIKISTÁN, LA "ÚLTIMA" FRONTERA DE EUROPA?}

La valoración de conflicto y su gestión se realiza desde una doble dimensión. La primera es la del conflicto en sí y las características que presenta. La crisis en Tayikistán, en tanto que guerra civil, fue la primera que afectó a la CEI, la entidad que subrogó en materia de cooperación política y militar, el espacio dejado por la Unión Soviética y del que la Federación Rusa se convirtió en centro y gestor. El conflicto coincide, en paralelo, a la formulación de un discurso y a la puesta en práctica de una política de corte "imperialista" y "colonialista", desde Moscú. Respecto a su naturaleza, el conflicto se distingue, como la mayoría que tienen lugar en el ámbito de la Nueva Europa, por su intraestatalidad como por su complejidad, rasgos que entrañan la dificultad de su gestión. En la 
línea de la complejidad, hay que resaltar junto a los factores históricos y culturales del conflicto, la importancia económica y estratégica que el Asia Central ha adquirido por los recursos energéticos existentes. No es baladí el interés en estabilizar la zona para asegurar la salida del petróleo y el gas. En este sentido, el conflicto en Tayikistán, es visto como "contaminador", difusor y hasta acelerador de conflictos en la zona (Uzbekistán, Kirguistán, Sinkiang (China), Kazajstán). Pero, también, es percibido como un revulsivo de políticas regionales, haciendo aparecer a actores poco activos hasta entonces, Irán y China, que aprovechan la crisis para incorporarse al "Gran Juego" y a las relaciones internacionales. Siguiendo la tónica de la complejidad, hay que señalar otro elemento significativo. En Tayikistán, se puede afirmar que existen distintas dinámicas conflictivas, la que padece el propio estado tayiko como tal (guerra civil, confrontación clánica, desestructuración económica, poder creciente del crimen organizado, reformulación del propio estado ¿existe?); la que enfrenta al gobierno estatal con entidades o grupos opositores (en particular grupos radicales islámicos) y la que tiene lugar de forma "subterránea" entre los distintos actores internacionales por el control geopolítico de la región. El conflicto también han puesto de manifiesto, las carencias, los desequilibrios, las "inestabilidades", en palabras de los especialistas, susceptibles de generar inseguridad, en la Cuenca del Caspio-Asia Central. El proceso político de la gestión del conflicto ha debido hacer frente, no sólo a como contener el enfrentamiento militar, sino también a otros temas como la violación de derechos humanos, los flujos de desplazados y refugiados, el déficit democrático, la reactivación de la economía, etc., que directamente inciden en las relaciones centroasiáticas.

La segunda dimensión de análisis es la del papel desempeñado por los actores internacionales y los encargados de gestionar el conflicto. Si bien los conflictos que tenían lugar en el territorio de la ex Unión Soviética constituían teóricamente una "window of opportuniy" para la actuación de las organizaciones internacionales, como la OSCE, ninguna participó en la gestión de situaciones conflictivas hasta la disolución oficial, diciembre de 1991. Hasta esa fecha se mantuvo a rajatabla la aplicación del principo de no injerencia en los asuntos internos de un estado (presente en Naciones Unidas y en la OSCE). Además, de ésta, otras circunstancias explican que las organizaciones se mantuviesen al margen. Una, ya apuntada, el tipo de conflictos, intraestatales, ante los que no había experiencia ni tampoco medios para actuar (códigos, principios consensuados, todo había sido pensado en función de relaciones entre estados y no para luchas clánicas), de ahí que la política que se aplicó fue de carácter, en algunos casos meramente reactivo (frente a las crisis, crear instrumentos, incluso ad hoc). Otra fue que la región consituía, constituye, parte del "extranjero" cercano" de la Federación y se debía contar con su beneplácito para actuar en la zona, tanto desde el ámbito de la OSCE como de Naciones Unidas. En este senti- 
do y desde 1992 el protagonismo ruso en los conflcitos de la ex-Unión Soviética se acrecienta de manera significativa tanto a nivel unilateral, como a través de la CEI. Lo que permite hablar del "factor ruso" para cualquier solución política en esa zona que se ha definido en términos de conflictividad como "zona de confusión". Las organizaciones internacionales, "legalizan" en muchos casos, la política de la Federación hacia la región. Ante el conflicto tayiko, y los del área en general, los actores internacionales han tenido una política muy clara, presionar para que el conflicto entre en vías de solución, y más desde setiembre de 2001. Si hace una década lo que sucedía en el complejo Cáucaso-Mar CaspioAsia Central, no interesaba a Occidente, hoy la región ocupa un lugar privilegiado en la agenda internacional. Quizás, la presencia de recursos enérgeticos el verdadero meollo de las relaciones en la zona-, su salida y su comercialización (para lo que se necesita estabilidad,) sea la carta a jugar para consolidar la solución precaria del conflicto. Así, Tayikistán, participante en la OSCE, en el único foro con calidad de europeo en el que está presente, aparece como el estado fractura, límite, confín o frontera (¿la última?) de la Nueva Europa. Mas allá están China, Irán o Afganistán, países, cuya situación en el actual sistema internacional constituye más una incertidumbre que una realidad.

\section{BIBLIOGRAFIA}

Adler, E. Y BarnetT, M. (1998): Security Communities, Cambridge, Cambridge University Press.

BRZEZINSKI, Z. (1997): The grand Chessboard. American Primacy and its Geostratégic Imperatives, Nueva York, Basic Books.

CARATINI, R. (1990): Dictionnaire des nationalités et des minorités en URSS, París Larousse.

CARrÈre D'ENCAUSSE, H. (1993): The End of the Soviet Empire. The Triumph of the Nations, NuevaYork, HarperCollins.

Deutsch, K. (1957): Political Community and the North Atlantic Area, Princeton, Princeton University Press

DJaliLi, M.R. (2001) «Nature et évolution des régimes politiques», Défense Nationale, n. 7, pp. 101-113 (monográfico sobre Asia Central)

DJALILI, M.R. Y KellneR, T. (2001) Geopolitique de la nouvelle Asie Centrale, París, PUF.

EBEL, R. (2001): «La politique américaine en Asie Centrale, inchangée mais souple», Défense Nationale, n. 8/9, pp. 80-88

FORSYTHE, R. (1996): «The Politics of Oil in the Caucasus and Central Asia», Adelphi Paper, núm. 300.

GHEBALI, V.Y. (1996): L'OSCE dans l'Europe post-commmuniste, 1990-1996. Vers une identité paneuropéenne de sécurité, Bruselas, Bruylant. 
GHEBALI, V.Y (2001): «Le rôle de l'OSCE en Asie Centrale», Défense Nationale, n. 7, pp. 122-127.

GRATCHEV, A. (1996): «La Russie à la recherche d'une politique étrangère», Notes et Études Documentaires, vol. 15-16, n. 5040-5041, pp. 113-123.

HAMBly, D. (1985): Asia Central, Madrid, Siglo XXI, Colección Historia Universal Siglo XXI, tomo 16.

HALliDAY (1995): «The Empires Strike Back? Russia, Iran and the New Republics», The World Today, vol. 51, núm. 1, pp. 220-222.

LLOYD, S. (1997) «Pipelines to Prosperity?», The International Spectator, vol. XXXII, núm. 1, pp. 52-60.

MOZAFFARI, M. (1995): «Explication typologyque des conflits du Caucase», en (DJAliLI, M., ed.) Le Caucase postsoviétique. La transition dans le conflit, Bruselas, Bruylant, pp. 197-220.

PARENTEAU, J.B. (1995): «La politique proche-étrangère de la Federation de Russie: ruptures et continuités», Notes de recherches, CEPES, Université de Quebec, n. 3.

RAMELOT, V. Y REMACLE, E. (1995): L'OSCE et le conflits en Europe, Bruselas, GRIP.

RASHID, A. (2002): Yihad. El auge del islamismo en Asia Central; Barcelona; Península.

ReITER, E. (2001): «New Global Politics: Reflectios on the Return of Geopolitics to Central Asia and Its Effects on European Security», en (GÄRTner, H.; Hyde-Price, A. Y ReITER, E.) Europe's New Security Challenges, Boulder,-Londres, Lynne Rienner, pp. 329-339.

RoBerts, J. (1996): Caspian Pipelines, Londres, Royal Institute of International Affairs.

RoY, O. (1998): La nueva Asia Central o la fabricación de naciones, Madrid, Sequitur.

RoY, O. (2001): L'Asie Centrale Contemporaine, París, PUF, [Colección Que sai-je?]

Singer, M. Y WiLDAVSKY, A. (1993) Real World Order, Zones of Peace/Zones of Turmoil, Chatham House, Chatham.

TAIBO, C. (1999): La Unión Soviética. El espacio ruso-soviético en el siglo XX, Madrid, Síntesis.

TinguY, A. de (2001): «De l'Asie Centrale au GUUAM: la relance de la Diplomatie Russe», Défense Nationale, N. 8/9, Pp. 69-79.

VIDAL-FOLCH, X. (1998): «l Caspio, recambio del Golfo Pérsico», El País (Suplemento Negocios) 15 de febrero, p. 18.

VVAA (1991): «En Asie Centrale Soviétique: Ethnies, Nations, États», Cahiers du Monde Russe et Soviétique, vol. XXXII, n. 1.

YAKEMTCHOUK, R. (1993) «Les conflits de territoire et de frontière dans les Etats 
de l'ex URSS», Annuaire français de droit international, vol. XXXIX, pp. 424-426.

RESUMEN: El trabajo aborda el conflicto en Tayikistán y su proceso de gestión internacional. La primera parte se centra en caracterizar la conflictividad en el ámbito de la Nueva Europa y la inserción del caso tayiko. La segunda, analiza el contexto general del conflicto en el Asia Central y la participación de actores internacionales en la región, así como las políticas generadas por éstos ante la presencia de importantes recursos energéticos. La tercera estudia la gestión llevada a cabo por Naciones Unidas y la OSCE, destacando el papel desempeñado por la Federación Rusa y la CEI en ese proceso de gestión.

PALABRAS CLAVE: Gestión de conflictos, Recursos energéticos, Tayikistán, Nueva Europa, Federación Rusa, OSCE, Naciones Unidas.

ABSTRACT: The work approaches the conflict in Tayikistán and its process of international administration. The first one leaves it centers in characterizing the conflict in the environment of the New Europe and the insert of the case tayiko. The second, analyze the general context of the conflict in the Central Asia and the participation of international actors in the region, as well as the politicians generated by these before the presence of important energy resources. The third study the administration carried out by United Nations and the OSCE, highlighting the paper carried out by the Russian Federation and the CEI in that administration process.

KEY WORDS: Conflict management, Energetic resources, Tayikistán, New Europe, Russia, OSCE, United Nations.

RÉSUMÉ: Le présent travail analyse le conflit en Tadjikistan et sa gestion internationale. La première partie montre les conflits au sein de la nouvelle Europe, notamment le cas tadjike. Dans un deuxième temps, on étudie le contexte général du conflit en Asie Centrale ainsi que la participation des intervenants internationaux dans la région et les politiques mises en place devant l'existence d'importantes ressources énergétiques. La troisième partie décrit la gestion menée par les Nations Unis et par l'OSCE, avec une mention spéciale du rôle joué par la Fédération russe et par la CEI dans cette gestion

MOTS-CLÉS: Gestion des conflits, Ressources énergétiques, Tadjiskitan, Nouvelle Europe, Russie, OSCE, Nations Unies.

RESUMO: O trabalho aborda o conflito no Tajiquistão e o seu processo de gestão internacional. A primeira parte centra-se em caracterizar a conflituosidade no âmbito da Nova Europa e a inserção do caso tajique. A segunda, analisa o contexto geral do conflito na Ásia Central e a participação de actores internacionais na região, assim como as políticas geradas por estes perante a presença de importantes recursos energéticos. A 
terceira estuda a gestão levada a cabo pelas Nações Unidas e a OSCE, destacando o papel desempenhado pela Federação Russa e a CEI nesse processo de gestão.

$\boldsymbol{P A L A V R A S ~ C H A V E : ~ G e s t a ̃ o ~ d e ~ c o n f l i t o s , ~ R e c u r s o s ~ e n e r g e ́ t i c o s , ~ T a j i q u i s t a ̃ o , ~ N o v a ~}$ Europa, Federação Russa, OSCE, Nações Unidas. 